\title{
Impact of glycaemic control, hypertension and insulin treatment on general and cause-specific mortality: an Italian population-based cohort of Type II (non-insulin-dependent) diabetes mellitus
}

\author{
G. Bruno ${ }^{1}$, F. Merletti ${ }^{2}$, P. Boffetta ${ }^{3}$, P. Cavallo-Perin ${ }^{1}$, G. Bargero ${ }^{4}$, G. Gallone ${ }^{2}$, G. Pagano ${ }^{1}$ \\ ${ }^{1}$ Department of Internal Medicine, University of Turin, Italy \\ ${ }^{2}$ Department of Biomedical Sciences and Human Oncology, University of Turin, Italy \\ ${ }^{3}$ Unit of Environmental Cancer Epidemiology, International Agency for Research on Cancer, Lyon, France \\ ${ }^{4}$ Ospedale S. Spirito, Casale Monferrato (Alessandria), Italy
}

\begin{abstract}
Summary The aims of this study were to assess the impact of diabetes and associated variables (fasting plasma glucose, blood pressure, antidiabetic treatment, body mass index) on general and cause-specific mortality in an Italian population-based cohort with Type II (non-insulin-dependent) diabetes mellitus, comprising mainly elderly patients. The patients $(n=$ 1967) who had Type II diabetes were identified in 1988 with an $80 \%$ estimated completeness of ascertainment. In 1995, a mortality follow-up (98\% completeness) of the cohort was done amounting to a total of 11153 person-years. Observed and expected number of deaths were 577 and 428.7, respectively, giving a standardized mortality ratio (SMR) of 1.35 (95\% CI 1.24-1.46). The most common underlying causes of death were malignant neoplasm, ischaemic heart disease and cerebrovascular diseases, which accounted for $18 \%, 17.8 \%$ and $17.5 \%$ of deaths, respectively. Cardiovascular disease as a whole (inter-
\end{abstract}

national classification of disease ICD-9 390-459) accounted for 260 of 577 deaths (SMR 1.21, 95\% CI 1.07-1.36). In internal analysis, the most important predictors of general mortality were insulin-treatment (relative risk [RR] 1.72, 95\% CI 1.19-2.49) and a fasting plasma glucose greater than $8.89 \mathrm{mmol} / \mathrm{l}$ ([RR] 1.29, 95\% CI 1.04-1.60), whereas the most important predictors of cardiovascular diseases were insulin-treatment and hypertension. In conclusion, this population-based study showed: 1) slight mortality excess of $35 \%$ in Type II diabetes being associated with 2) a $30 \%$ increased mortality in subjects with baseline fasting glucose greater than $8.89 \mathrm{mmol} / \mathrm{l}$ and 3) a $40 \%$ increased risk of death from cardiovascular diseases in hypertensive patients. [Diabetologia (1999) 42: 297-301]

Keywords Mortality, cardiovascular diseases, hypertension, stroke, obesity, Type II diabetes.
In middle-aged diabetic subjects a two-fold to fourfold increased mortality compared with the general population has been reported [1], with wide variations depending on the country [2]. Declining mortality risk with advancing age, and almost no excess mortality in those aged over 75 years, has also been suggested. Most mortality studies have, however, been hampered by great variation in diagnostic crite-

Received: 27 July 1998 and in final revised form: 17 November 1998

Corresponding author: G. Bruno, Dipartimento di Medicina Interna, corso Dogliotti 14, I-10126 Torino, Italy

Abbreviations: SMR, Standardized mortality ratio; ICD, international classification of disease; RR, relative risk ria and study design. In particular clinic-based cohorts are possibly not representative of the overall diabetic population, since diabetic patients attending hospital clinics are generally selected for severity of disease. In European countries few population-based studies are available [3-4].

In this report we assessed the impact of diabetes and associated variables (fasting plasma glucose, blood pressure, antidiabetic treatment, BMI) on general and cause-specific mortality in an Italian population-based cohort with Type II (non-insulin-dependent) diabetes mellitus comprising mainly elderly patients. 


\section{Subjects and methods}

The study base was 1967 patients ( 838 men; 1129 women) with Type II diabetes resident in the area of Casale Monferrato (Northern Italy) on 1 October 1988. They were part of a cohort, identified in a prevalence survey, of 2069 diabetic patients ( 77 with Type I [insulin-dependent] diabetes mellitus, 1967 with known Type II, 25 unclassified), drawn from multiple sources: 1) diabetes clinics; 2) general practitioners; 3 ) hospital discharges; 4) prescriptions; 5) sale records of reagent strips and syringes [5-6]. Completeness of ascertainment was estimated by using capture-recapture methods to be $80 \%$ [7]. In all patients, the accuracy of previous diagnosis of diabetes mellitus was verified with the collaboration of general practitioners, using criteria defined by the National Diabetes Data Group (NDDG); patients were visited during their periodic appointment either at the diabetes clinic or at the general practitioner's office. At the baseline survey, the height and weight of the subjects (in indoor clothing without shoes) were measured with a beam balance and a stadiometer and BMI was calculated as body weight $(\mathrm{Kg})$ divided by height $\left(\mathrm{m}^{2}\right)$ Blood pressure was measured with a mercury sphygmomanometer in the patient's right arm with the patient in a sitting position. Hypertension was defined as systolic blood pressure $160 \mathrm{~mm} \mathrm{Hg}$ or more or diastolic blood pressure $95 \mathrm{~mm} \mathrm{Hg}$ or more or treatment with antihypertensive drugs. Information was collected on the date of first diagnosis of diabetes and on current treatment.

In 1995, a mortality follow-up of the cohort was carried out. Information as to which subjects had died was obtained from the demographical files of towns of their residence or death. As 26 patients were lost there was a $98.7 \%$ completeness of follow-up. The underlying cause of death was derived and coded by two of the authors, according to the 9 th revision of the International Classification of Disease (ICD) from that reported on the death certificate. The expected numbers of deaths were calculated by multiplying the number of person-years in each sex, 5-year age and calendar period for the mortality rates of the Italian population derived from the World Health Organisation (WHO) mortality database. The standardized mortality ratio (SMR) was defined as the ratio of observed to expected deaths. We calculated $95 \%$ confidence intervals (CIs) of the SMR assuming a Poisson distribution of observed deaths. Relative risks of all causes of mortality were estimated by means of multivariate Poisson regression [8]. Sex, age (5-year groups), calendar period (10-year-groups), duration of diabetes (10-year-groups) and referring physician were included in the basic model. Also included in the model were antidiabetic treatment, hypertension, fasting plasma glucose (tertiles), BMI $\left(<25 ; 25-29 ; 30+\mathrm{kg} / \mathrm{m}^{2}\right)$ and smoking (never; former; current smoker).

\section{Results}

Mean ages ( \pm standard deviation) at cohort identification and at diagnosis were $64 \pm 10.6$ years and $57.4 \pm 11.3$ years for men, and $68.4 \pm 10.7$ and $60.0 \pm 11.6$ years for women, respectively. Mean duration of diabetes was $8.5 \pm 7.0$ years. The prevalence of hypertension was $45.0 \%$ for men and $51.5 \%$ for women; $26 \%$ of subjects were exclusively cared for by general practitioners. Mean fasting plasma glucose was $8.5 \pm 2.6 \mathrm{mmol} / \mathrm{l}$. Patients treated with diet, oral hypoglycaemic drugs and insulin (alone or combined with oral drugs) were $10.3 \%, 76.2 \%, 10.0 \%$ and $3.5 \%$, respectively. The study cohort represents a total of 11153 person-years of observation.

A total of 577 patients ( 249 men and 328 women) died between 1 October 1988 and 30 June 1995. Expected numbers of deaths were 428.7, giving an SMR of 1.35 (95\% CI 1.24-1.46). No differences between the sexes (Table 1) but a strong negative gradient of SMRs with increasing age was evident; 2.62 (95\% CI $1.83-3.62)$ at ages under 60 years, $1.86(1.52-2.25)$ at ages $60-69$ years, $1.37(1.18-1.58)$ at ages $70-79$ years and $1.12(0.98-1.27)$ at ages over 80 years.

Cardiovascular disease as a whole (ICD-9 390-459) accounted for 260 of 577 deaths (SMR $1.21,95 \%$ CI 1.07-1.36). In both sexes, there were more deaths from ischaemic and cerebrovascular diseases but no increase in mortality from either malignant neoplasms or other causes of death was evident.

In internal analysis, no effect on mortality was found for duration of diabetes, referring physician, blood pressure and BMI. The most important predictors of general/cardiovascular diseases were insulintreatment and fasting plasma glucose greater than $8.89 \mathrm{mmol} / \mathrm{l} /$ insulin-treatment (association not statistically significant) and hypertension (Table 2). The effect of glycaemic control on mortality was more pronounced though not significant for cerebrovascular diseases. Antidiabetic treatment was an important predictor of ischaemic heart disease, with an almost 3 times higher risk of death in subjects treated with insulin and 2.5 times higher risk in subjects treated with a combination of oral hypoglycaemic drugs. In contrast, no effect of antidiabetic treatment on risk of death from cerebrovascular diseases was found. The inclusion in the model of smoking did not modify relative risks of estimated variables. The results were essentially similar when the data were analysed separately for men and women.

We also analysed whether the predictive value of fasting plasma glucose with respect to all-cause and cause-specific mortality was modified by antidiabetic treatment, BMI, duration of disease or hypertension (Table 3). Antidiabetic treatment and fasting plasma glucose were independently associated with all-cause mortality, with the highest RRs in insulin-treated subjects who had fasting plasma glucose concentrations $7.21 \mathrm{mmol} / \mathrm{l}$ or more. In contrast, in the highest tertile of fasting plasma glucose $(>8.89 \mathrm{mmol} / \mathrm{l})$, no effect of treatment was evident. No clear effect of BMI, duration of diabetes and blood pressure per se was observed. In fact, at all levels of these variables, the highest RR values were found in the highest tertile of fasting plasma glucose. This did not apply to obese subjects $\left(B M I \geq 30 \mathrm{~kg} / \mathrm{m}^{2}\right)$. 
Table 1. Mortality in patients with Type II diabetes in Casale Monferrato (Italy), by selected causes of death and sex

\begin{tabular}{|c|c|c|c|c|}
\hline \multirow[t]{2}{*}{ Causes of death ICD-9 } & \multicolumn{2}{|l|}{ Men } & \multicolumn{2}{|l|}{ Women } \\
\hline & Expected deaths & $\overline{\text { SMR }(95 \% \mathrm{CI})}$ & Expected deaths & SMR $(95 \%$ CI $)$ \\
\hline $\begin{array}{l}\text { Malignant neoplasms } \\
(140-208)\end{array}$ & 52.9 & $0.98(0.73-1.29)$ & 43.2 & $1.27(0.96-1.66)$ \\
\hline $\begin{array}{l}\text { Cardiovascular diseases } \\
(390-459)\end{array}$ & 84.2 & $1.32(1.08-1.59)$ & 131.0 & $1.14(0.96-1.34)$ \\
\hline $\begin{array}{l}\text { Ischaemic heart disease } \\
(410-414)\end{array}$ & 27.5 & $1.67(1.22-2.23)$ & 29.7 & $1.92(1.45-2.49)$ \\
\hline $\begin{array}{l}\text { Respiratory system diseases } \\
(460-519)\end{array}$ & 17.1 & $1.34(0.85-2.01)$ & 13.9 & $0.79(0.40-1.42)$ \\
\hline $\begin{array}{l}\text { Digestive system diseases } \\
(520-579)\end{array}$ & 10.9 & $1.01(0.50-1.81)$ & 10.5 & $1.71(1.02-2.71)$ \\
\hline $\begin{array}{l}\text { Genitourinary system diseases } \\
(580-629)\end{array}$ & 3.1 & $1.63(0.53-3.81)$ & 3.0 & $1.33(0.36-3.40)$ \\
\hline All causes & 189.7 & $1.31(1.15-1.49)$ & 239.0 & $1.37(1.23-1.53)$ \\
\hline
\end{tabular}

Table 2. Selected clinical variables and mortality in patients with Type II diabetes in Casale Monferrato (Italy)

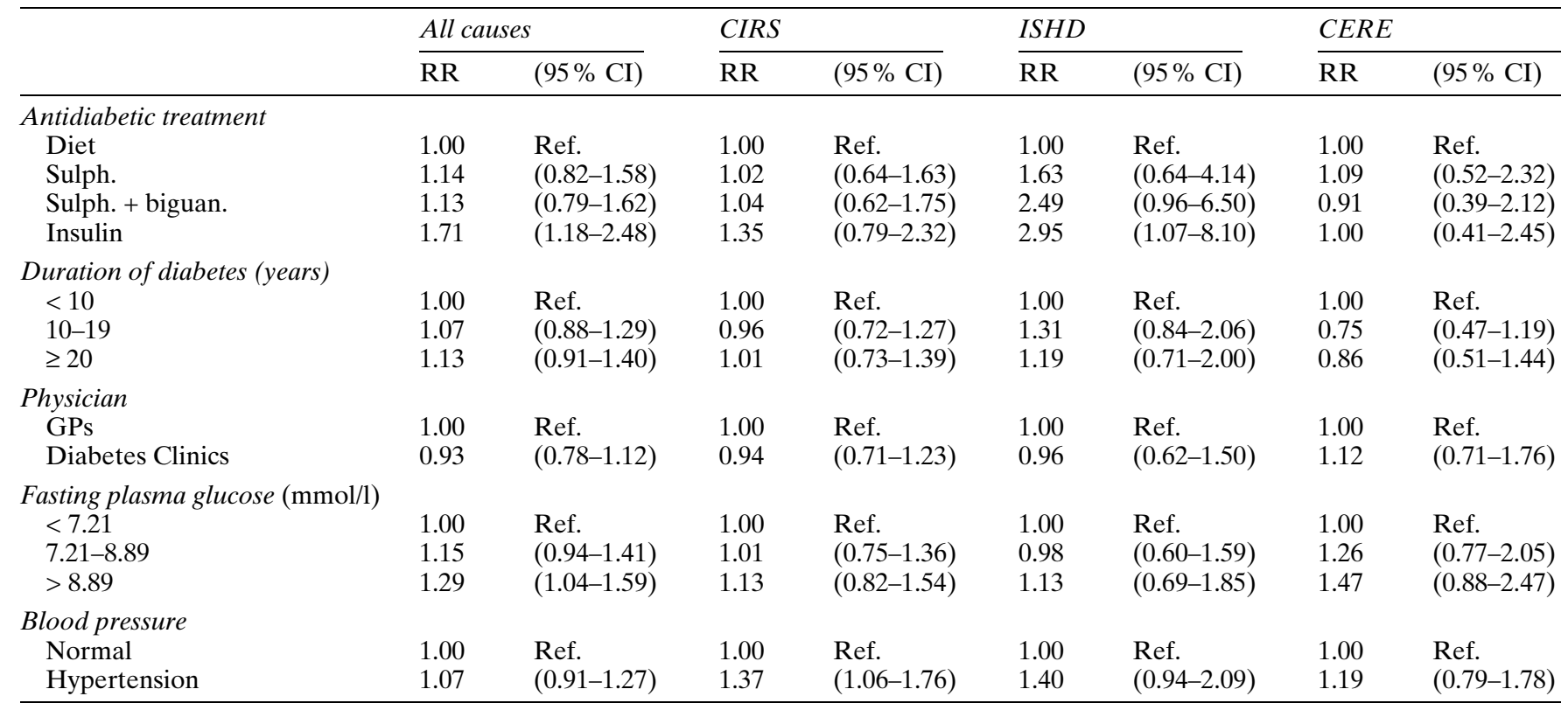

CIRS, cardiovascular diseases; ISHD, ischaemic heart disease (ICD-9 410-414); CERE, cerebrovascular disease (ICD-9 430-438); RR, relative risk adjusted for sex, age, calendar period, duration of diabetes and referring physician; GP, general

practitioner; Ref., Reference category; Sulph., sulphonylurea drugs; biguan., biguanides.

Note no effect on mortality was found for BMI

\section{Discussion}

In this Italian population-based cohort, patients with Type II diabetes showed only a $35 \%$ increased mortality risk compared with non diabetic subjects. Most of the negative impact of the disease was, however, present in subjects in the younger age-group (2.6fold increased risk in subjects $<60$ years), which rep- resented $27 \%$ of the cohort. This finding, which was not confounded by duration of the disease, is relevant for public health planning, emphasising the need for prevention of the disease and its complications in the young.

Only two population-based mortality studies have been carried out on large European cohorts of patients diagnosed with diabetes according to National 
Table 3. Effect modification of blood fasting glycaemia (tertiles) on selected variables on all-cause mortality in patients with Type II diabetes in Casale Monferrato (Italy)

\begin{tabular}{|c|c|c|c|}
\hline & \multicolumn{3}{|c|}{ Fasting plasma glucose $(\mathrm{mmol} / \mathrm{l})$} \\
\hline & $<7.21$ & $7.21-8.89$ & $>8.89$ \\
\hline \multicolumn{4}{|c|}{ Antidiabetic treatment } \\
\hline OAD & $1.34(0.79-2.25)$ & $1.53(0.91-2.57)$ & $1.56(0.92-2.64)$ \\
\hline Insulin & $1.82(0.96-3.45)$ & $2.40(1.28-4.50)$ & $2.57(1.45-4.53)$ \\
\hline \multicolumn{4}{|l|}{$B M I\left(\mathrm{~kg} / \mathrm{m}^{2}\right)$} \\
\hline$\geq 30$ & $0.96(0.64-1.44)$ & $1.14(0.81-1.61)$ & $1.07(0.74-1.53)$ \\
\hline \multicolumn{4}{|c|}{ Duration of diabetes (years) } \\
\hline$<10$ & 1.00 Ref. & $1.08(0.82-1.44)$ & $1.33(0.99-1.81)$ \\
\hline $10-19$ & $0.97(0.70-1.35)$ & $1.29(0.94-1.77)$ & $1.28(0.94-1.76)$ \\
\hline$\geq 20$ & $1.15(0.74-1.80)$ & $1.18(0.79-1.76)$ & $1.33(0.91-1.95)$ \\
\hline \multicolumn{4}{|l|}{ Blood pressure } \\
\hline
\end{tabular}

Relative risks (RR) and (95\% confidence intervals).

All RRs controlled for age, sex, calendar period and referring physician.

Ref., reference category; OAD, oral antidiabetic agents

Diabetes Data Group criteria. In the first study a similar mortality risk was found (SMR 1.15, $95 \%$ CI 1.08-1.22) in a Scottish community, where patients with Type I diabetes represented almost $31 \%$ of the whole cohort [3]. This figure is far apart from ours of $4 \%$ patients with Type I diabetes and, even considering the 2-3 fold lower incidence of the disease in our area than in Scotland, indicates a likely overpresentation of Type I diabetic patients. The second population-based study was done in Verona in Italy and provided a similar result on all-cause mortality in Type II diabetes (SMR 1.44, 95 \% CI 1.36-1.53) [4]. No attempt to assess the completeness of the cohort was described so that the extent of selection bias cannot be evaluated. Whether the fact that both available Italian studies provide a relatively low all-cause SMR is due to a specific favourable state of Italian diabetic patients, most of which are currently attending National Health Service diabetes clinics, remains to be assessed. Studies done on selected groups of patients who attend the diabetes clinic could be biased as general practitioners tend to selectively refer younger patients and those with poorer fasting plasma glucose to the diabetes clinic [6]. In our study, lost subjects were those who did not attend a diabetes clinic and a slightly lower prevalence of poor blood glucose control in these subjects is likely. Such bias in the referral causes a slight overestimation of SMRs. Thus, assuming that the mortality of the missing patients is only $75 \%$ of that of those included, the overall SMR would decrease from 1.35 to 1.28 (95\% CI 1.19-1.38).

In our study baseline glycaemic control is related to all-cause mortality, with a $30 \%$ higher risk in subjects with fasting plasma glucose over $8.89 \mathrm{mmol} / \mathrm{l}$.
The increase in deaths from cardiovascular diseases is weaker $(13 \%)$, mainly due to cerebrovascular disease $(47 \%)$ and consistent with the hypothesis of worsening brain damage in the presence of higher glucose concentrations. Involvement of glycaemic control in atherosclerotic disease has been suggested by a Finnish study, showing a two-fold increased mortality in subjects aged 45-64 years with baseline fasting glucose in the highest tertile $(>13.4 \mathrm{mmol} / \mathrm{l})$ compared with those with values in the lower tertile $(<9.6 \mathrm{mmol} / \mathrm{l})$, together with an increase in cardiovascular morbidity in surviving subjects [9]. In our diabetic group, comprising mainly elderly subjects with only moderately impaired glucose tolerance, lower fasting glucose concentrations were found. Accordingly, the highest and the lowest tertiles of blood glucose distribution were defined by more than $8.89 \mathrm{mmol} / \mathrm{l}$ and less than $7.21 \mathrm{mmol} / 1$, respectively. Our finding of increased mortality even in this span of fasting blood glucose distribution is remarkable, suggesting a negative impact of hyperglycaemia in a large proportion of the diabetic population. The few other studies examining the relation between hyperglycaemia and mortality risk have consistently found an association between these conditions [10-13]. Overall, they suggested that the association between cardiovascular diseases and glycaemia is weaker than that observed for the other risk factors [14]. In the Verona Study, instability of fasting plasma glucose rather than average value over 3 years was shown to predict all-cause and cardiovascular mortality in diabetic patients older than 75 years [15]. In that study, however, only patients attending the diabetes clinic were retrospectively evaluated, so that bias cannot be ruled out because macrovascular dis- 
eases impairing patients' autonomy could have reduced the clinic attendance, giving an underestimation of the effect.

A higher risk of death from cardiovascular diseases, with $40 \%$ increased risk for ischaemic heart disease, was found in hypertensive patients, confirming the negative impact of this condition in diabetic patients. The association of antidiabetic treatment with ischaemic heart disease mortality is of note, indicating a 2.5-fold increase in risk of death in patients treated with both sulphonylurea drugs and biguanides and a 3-fold increase in those treated with insulin. No effect of antidiabetic treatment was observed on cerebrovascular diseases. Our results though should be interpreted with caution because of the relatively small numbers of events.

No evidence was found of an association between mortality and BMI which is consistent with the WHO Multinational Study of Vascular Disease in Diabetes [16].

In conclusion, this population-based study showed: 1) a slight overall excess of mortality (35\%) in Type II diabetes; 2) a 30\% increased mortality in patients with baseline fasting glucose over $8.89 \mathrm{mmol} / \mathrm{l}$ and 3) a $40 \%$ increased risk of death from cardiovascular diseases in hypertensive diabetic patients.

Acknowledgements. The authors are grateful to C. Didier, International Agency for Research on Cancer, for his contribution to data analysis. This work was partially supported by AIRC (Associazione Italiana per la Ricerca sul Cancro) and by Ministero della Università e della Ricerca Scientifica e Tecnologica (MURST), Italy.

\section{References}

1. Panzram G (1987) Mortality and survival in Type 2 (noninsulin-dependent) diabetes mellitus. Diabetologia 30: 123-131

2. Head J, Fuller JH (1990) International variation in mortality among diabetic patients: the WHO Multinational Study of Vascular Diasease in Diabetics. Diabetologia 33: 477-481

3. Wong JSK, Pearson DWM, Murchison LE, Williams MJ, Narayan V (1990) Mortality in diabetes mellitus: expe- rience of a geographically defined population. Diabet Med 8: 135-139

4. Muggeo M, Verlato G, Bonora E et al. (1995) The Verona Diabetes study: a population-based survey on known diabetes mellitus prevalence and 5-year all-cause mortality. Diabetologia 38: 318-325

5. Bruno G, Bargero G, Vuolo A, Pisu E, Pagano G (1992) A population-based prevalence survey of known diabetes mellitus in Northern Italy based upon multiple independent sources of ascertainment. Diabetologia 35: 851-856

6. Pagano G, Bargero G, Vuolo A, Bruno G (1994) Prevalence and clinical features of known type 2 diabetes in the elderly: a population-based study. Diabet Med 11: 475-479

7. Bruno G, LaPorte RE, Merletti F, Biggeri A, McCarty D, Pagano G (1994) National diabetes programs. Application of capture-recapture to count diabetes? Diabetes Care 17: 548-556

8. Breslow NE, Day NE (1987) Statistical methods in cancer research, vol 11. The Design and Analysis of cohort studies. International Agency for Research on Cancer, Lyon

9. Lehto S, Ronnemaa T, Haffner SM, Pyorala K, Kallio V, Laakso M (1997) Dyslipidemia and hyperglycemia predict coronary heart disease events in middle-aged patients with NIDDM. Diabetes 46: 1354-1359

10. Andersson DKG, Svardsudd K (1995) Long term glycemic control relates to mortality in type II diabetes. Diabetes Care 18: 1534-1543

11. Lowe LP, Liu K, Greenland P, Metzger BE, Dyer AR, Stamler J (1997) Diabetes, Asymptomatic hyperglycemia, and 22-year mortality in black and white men. Diabetes Care 20: 163-169

12. Moss SE, Klein R, Klein BE, Meuer SM (1994) The association of glycemia and cause specific mortality in a diabetic population. Arch Intern Med 154: 2473-2479

13. Gall MA, Borch-Jonsen K, Hougaard P, Nielsen FS, Parving $\mathrm{H}$ (1995) Albuminuria and poor glycaemic control predict mortality in NIDDM. Diabetes 44: 1303-1309

14. UK Prospective Diabetes Study (UKPDS) Group (1988) Intensive blood-glucose control with sulphonylureas or insulin compared with conventional treatment and risk of complications in patients with type 2 diabetes (UKPDS 33). Lancet 352: 837-853

15. Muggeo M, Verlato G, Bonora E et al. (1995) Long-term instability of fasting plasma glucose predicts mortality in elderly NIDDM patients: the Verona Diabetes Study. Diabetologia 38: 672-679

16. Chaturvedi N, Fuller JH, The WHO Multinational Study Group (1995) Mortality risk by body weight and weight change in people with NIDDM. The WHO Multinational Study of Vascular Disease in Diabetes. Diabetes Care 18: 766-774 